\title{
Tyrosine Phosphorylation of the Kv1.3 Potassium Channel
}

\author{
Todd C. Holmes, Debra A. Fadool, and Irwin B. Levitan \\ Volen Center for Complex Systems and Graduate Department of Biochemistry, Brandeis University, \\ Waltham, Massachusetts 02254
}

$\mathrm{Kv1.3}$, a voltage-dependent potassium channel cloned from mammalian brain and $\mathrm{T}$ lymphocytes, contains multiple tyrosine residues that are putative targets for tyrosine kinases. We have examined the tyrosine phosphorylation of Kv1.3, expressed transiently in human embryonic kidney (or HEK) 293 cells, by endogenous and coexpressed tyrosine kinases. Tyrosine phosphorylation is measured by a strategy of immunoprecipitation followed by Western blot analysis, using antibodies that specifically recognize Kv1.3 and phosphotyrosine. Coexpression of the constitutively active tyrosine kinase $v$-src, together with $\mathrm{Kv1.3}$, causes a large increase in the tyrosine phosphorylation of the channel protein. This phosphorylation of Kv1.3 can be reversed by treatment with alkaline phosphatase before Western blot analysis. Coexpression with a receptor tyrosine kinase, the human epidermal growth factor receptor, also causes an increase in tyrosine phosphorylation of Kv1.3. The effects of endogenous tyrosine kinases were examined by treating Kv1.3-transfected cells with the specific membrane-permeant tyrosine phosphatase inhibitor pervanadate. Pervanadate treatment causes a time- and concentrationdependent increase in the tyrosine phosphorylation of Kv1.3. This increased tyrosine phosphorylation of Kv1.3 is accompanied by a time-dependent decrease in Kv1.3 current, measured by patchclamp analysis with cell-attached membrane patches. The pervanadate-induced suppression of current and much of the channel tyrosine phosphorylation are eliminated by mutation of a specific tyrosine residue, at position 449 of Kv1.3, to phenylalanine. Thus, there is a continual phosphorylation and dephosphorylation of Kv1.3 by endogenous kinases and phosphatases, and perturbation of this constitutive phosphorylation/dephosphorylation cycle can profoundly influence channel activity.

Key words: ion channels; neuromodulation; tyrosine kinases; tyrosine phosphatases; src; epidermal growth factor receptor; pervanadate
Cellular electrical activity underlies a wide variety of physiological processes, including information processing in the nervous system (Llinas, 1988). The electrical activity of nerve (and other) cells is mediated by ion channels. Ion channels are subject to dynamic regulation, which is often referred to as modulation (Kaczmarek and Levitan, 1987). Thus, information about mechanisms that regulate ion channel activity (Levitan, 1994) is essential for even the most rudimentary understanding of neuronal function.

Protein phosphorylation is one of the best characterized mechanisms of ion channel modulation (Levitan, 1994). Ion channel modulation by Ser and Thr protein kinases has been studied extensively, and $\mathrm{K}^{+}$channels are among those subject to Ser/Thr phosphorylation (Busch et al., 1992; Covarrubias et al., 1994; Drain et al., 1994). Kv1.3 is a member of the Shaker-like $\mathrm{K}^{+}$ channel subfamily, which includes channels that were referred to previously as voltagc-dependent A-type or delayed rectifier $\mathrm{K}^{+}$ channels based on their kinetic properties. Kv1.3 is localized selectively to several different regions of rat brain (Kues and Wunder, 1992) and is the major voltage-dependent $\mathrm{K}^{+}$channel in T lymphocytes (Cahalan et al., 1985; Douglass et al., 1990; Grissmer et al., 1990; Attali et al., 1992b). There is evidence for the modulation of functional activity of Kv1.3 (Attali et al., 1992a; Payet and Dupuis, 1992) and direct biochemical phosphorylation

Received Oct. 27, 1995; revised Oct. 27, 1995; accepted Dec. 4, 1995.

This research was supported by a grant to I.B.L. from National Institutes of Health. T.C.H. was supported by a National Institutes of Health Institutional Training Grant. We thank Jill Swartz and Kevin Berman for their assistance with some of these experiments, and we thank Kevin Berman for construction of the Y449F Kv1.3 mutant channel.

Correspondence should be addressed to Irwin B. Levitan at the above address.

Copyright $\mathbb{C} 1996$ Society for Neuroscience $0270-6474 / 96 / 161581-10 \$ 05.00 / 0$ of this channel protein (Cai and Douglass, 1993) by Ser/Thr protein kinases.

In contrast, the role of tyrosine phosphorylation of ion channels has only begun to be investigated (Hopfield et al., 1988; Huang et al., 1993; Wilson and Kaczmarek, 1993; Timpe and Fantl, 1994; Wang and Salter, 1994). Ion channels are among the many proteins that contain sequences that mediate substrate specificity and targeting of tyrosine kinases (Pawson, 1995). Many tyrosine kinases, including the human epidermal growth factor receptor (EGFr) and src family kinases, recognize nearby glutamate or aspartate residues at sites flanking the phosphorylated tyrosine (Songyang et al., 1995). Kv1.3 has a number of tyrosine residues that lie within such potential consensus sequences for different classes of tyrosine kinases. To determine whether Kv1.3 is a target for endogenous and coexpressed tyrosine kinases, we used a mammalian heterologous expression system combined with immunoprecipitation/Western blot analysis, using specific antibodies that recognize tyrosine-phosphorylated proteins and Kv1.3. Furthermore, we examined the functional consequences of Kv1.3 tyrosine phosphorylation using patch-clamp analysis. The results indicate that Kv1.3 is an excellent substrate for several different tyrosine kinases, and that tyrosine phosphorylation of the channel modulates its functional properties.

\section{MATERIALS AND METHODS}

cDNA expression vectors and site-directed mutagenesis. All mammalian expression vectors used for these experiments contained the cytomegalovirus (CMV) promoter upstream from the coding region. The plasmid $\mathrm{pRc}-\mathrm{CMV}$ (Invitrogen, San Diego, CA) was used as the control vector for all experiments. Kv1.3 cDNA, generously provided by Dr. Richard Swanson (Merck, Sharp, and Dohme Research Laboratories, West Point, PA), was inserted into pRc-CMV by Dr. Mark Bowlby (Bowlby and Levitan, 
1995). The cDNAs for v-src kinase (v-src) and the human EGFr were generously provided by Dr. Richard Huganir (Johns Hopkins University, Baltimore, MD). Site-directed mutagenesis was used to construct a mutant Kv1.3 channel in which tyrosine residue 449 is mutated to phenylalanine. A single PCR using a mutagenic primer and a wild-type primer was used to introduce the mutation. The PCR was run in a thermocycler (Eri-Comp, Twin Block System, San Diego, CA) using Taq polymerase (Promega, Madison, WI). The PCR product was cut sequentially with BsteII (Promega) and BbrP1 (Boehringer Mannheim, Indianapolis, IN) with a phenol/chloroform extraction and ethanol precipitation between cuts. An identical protocol was used to cut wild-type Kv1.3 in the $\mathrm{pRc} / \mathrm{CMV}$ vector to construct a backbone. The desired pieces were gel-purified (Gene-Clean II, Bio Labs 101, Vista, CA) from a $2 \%$ agarose gel, and the mutagenic insert was ligated into the Kv1.3-pRc/CMV backbone using T4 DNA ligase (Promega). The sequence between the Bstell and BbrP1 sites was confirmed using an automated sequencer.

Cell culture and transfection procedures. Cells were maintained in modified eagle medium (MEM) containing $2 \%$ penicillin/streptomycin and $10 \%$ fetal bovine serum (Gibco, Grand Island, NY). Cells were grown to confluency (1 week), dissociated with trypsin-EDTA (Gibco) and mechanical trituration, diluted in MEM to a concentration of $\sim 600$ cells $/ \mu 1$, and replated on Corning plastic dishes \#25000 (Dow Corning, Corning, NY). cDNAs coding for Kv1.3, Y449F Kv1.3, v-src, EGFr, or control vector were introduced into human embryonic kidney cells (HEK 293) (Graham et al., 1977) by lipofectamine transfection (Gibco). Briefly, cells were transfected 3-5 d after recovery from cell passage, at either $70-80 \%$ (biochemistry) or 20-30\% (electrophysiology) confluency. The total amount of cDNA used for transfection was the same for all control and experimental groups. Cells were transfected with either $5 \mu \mathrm{g}$ of DNA/60 $\mathrm{mm}$ dish (biochemistry) or $1 \mu \mathrm{g}$ of DNA/35 mm dish (electrophysiology).

For Kv1.3/tyrosine kinase coexpression experiments, cells were transfected with a total of $10 \mu \mathrm{g}$ of DNA/60 mm dish $(5 \mu \mathrm{g}$ of DNA of each construct coding for Kv1.3 and tyrosine kinases; the channel or kinase alone groups were brought up to $10 \mu \mathrm{g}$ of DNA with the addition of $5 \mu \mathrm{g}$ of vector-control cDNA). Cotransfection control cells were transfected with $10 \mu \mathrm{g}$ of vector-control DNA/60 mm dish. Cells were incubated for $5 \mathrm{hr}$ with the lipofectamine/DNA mixture diluted in serum-reduced medium (OptiMEM, Gibco). Transfection efficiency was monitored in parallel plates by staining for the $\beta$-galactosidase reaction product in LacZ expression plasmid-transfected cells. Staining efficiency (blue cells) normally ranged from 70 to $90 \%$. Expression of the Kv1.3 channel protein could be detected immunochemically in as little as $24 \mathrm{hr}$, and was sufficient to produce macroscopic currents in cell-attached membrane patches 24-72 hr after transfection (Bowlby and Levitan, 1995).

Pervanadate preparation and treatment. For biochemical experiments, pervanadate was prepared by a 2 min incubation of $\mathrm{Na}_{3} \mathrm{VO}_{4}$ and $\mathrm{H}_{2} \mathrm{O}_{2}$, followed by dilution to the appropriate final concentration $(0-250 \mu \mathrm{M}$ pervanadate; $0.0008 \% \mathrm{H}_{2} \mathrm{O}_{2}$ ) in serum-free MEM. Cells were incubated with pervanadate in MEM for the times indicated. For electrophysiological experiments, pervanadate was prepared by mixing $\mathrm{Na}_{3} \mathrm{VO}_{4}$ in bath solution (see below) with $\mathrm{H}_{2} \mathrm{O}_{2}$ for 20 min followed by the addition of 54 $\mu \mathrm{M}$ catalase for 5 min to quench any residual $\mathrm{H}_{2} \mathrm{O}_{2}$ (Fantus et al., 1989). The final concentrations in the bath solution were $100 \mu \mathrm{M}$ pervanadate and $0.003 \% \mathrm{H}_{2} \mathrm{O}_{2}$. After achieving a cell-attached patch configuration, cells were treated first with bath solution $+0.003 \% \mathrm{H}_{2} \mathrm{O}_{2}+54 \mu \mathrm{M}$ catalase for $10 \mathrm{~min}$ to ensure that there was no effect of the $\mathrm{H}_{2} \mathrm{O}_{2}$ alone. The bath was then replaced with the pervanadate-containing solution for the duration of the patch recording.

Cell lysis and immunoprecipitation. Cells were harvested $2 \mathrm{~d}$ after transfection by lysis in ice-cold $1 \%$ Triton X-100-modified immunoprecipitation buffer (Sambrook et al., 1989) containing protease and phosphatase inhibitors (25 mM Tris, pH 7.5, $150 \mathrm{~mm} \mathrm{NaCl}, 100 \mathrm{~mm} \mathrm{NaF}, 5 \mathrm{~mm}$ EDTA, $1 \mathrm{~mm} \mathrm{Na} \mathrm{VO}_{4}, 1 \%$ Triton $\mathrm{X}-100,1 \mathrm{~mm}$ phenylmethylsulfonyl fluoride, $1 \mu \mathrm{g} / \mathrm{ml}$ leupeptin, and $2 \mu \mathrm{g} / \mathrm{ml}$ aprotinin). The cell lysates were clarified by centrifugation $\left(15,000 \times \mathrm{g}, 5 \mathrm{~min}, 4^{\circ} \mathrm{C}\right)$. To immunoprecipitate lysate proteins from the supernatant, we used a $2 \mathrm{hr}$ incubation with antibody ( $5 \mu \mathrm{g}$ antibody $/ \mathrm{ml}$ cell lysate, see below) at $4^{\circ} \mathrm{C}$ followed by an overnight incubation with protein-A Sepharose $(3 \mathrm{mg} / \mathrm{ml}$ cell lysate; Pharmacia, Piscataway, NJ) at $4^{\circ} \mathrm{C}$. The immunoprecipitates were washed three times with ice-cold $0.1 \%$ Triton X-100-modified immunoprecipitation buffer ( 200 vol wash buffer/vol immunoprecipitate pellet). Lysate samples and washed immunoprecipitates were diluted in SDS-gel loading buffer (Sambrook et al., 1989).

Western blot and autoradiogram procedures. Proteins were separated on $10 \%$ acrylamide gels by SDS-PAGE and electrotransferred to nitrocellulose blots (Sambrook et al., 1989). The blots were blocked in 5\% nonfat milk and incubated overnight in primary antibody at $4^{\circ} \mathrm{C}$. They were then incubated with horseradish peroxidase (HRP)-conjugated secondary antibody (Amersham, Arlington Heights, IL) for $2 \mathrm{hr}$ at room temperature. Enhanced chemiluminescence (ECL; Amersham) exposure on XAR-2 film (Kodak, Rochester, NY) was used to visualize labeled protein. The magnitude of the signal is directly related to the amount of HRP-conjugated secondary antibody. The film autoradiograms were analyzed by densitometry using a Bio-Rad model GS-670 imaging densitometer (Bio-Rad, Hercules, CA). Relative densitometry values were determined to be linear by serial dilution of protein samples used for Western immunoblotting.

Antibodies and reagents. Tyrosine-phosphorylated proteins were immunoprecipitated and detected by Western blot with the mouse monoclonal antibody 4G10 (Upstate Biochemical, Lake Placid, NY) that recognizes phosphotyrosine. The specificity of $4 \mathrm{G10}$ was verified by preabsorption with phosphotyrosine. Tyrosine, phosphoserine, and phosphothreonine preabsorption of 4G10 do not effect anti-phosphotyrosine immunostaining. Another anti-phosphotyrosine antibody, mouse monoclonal PY20 (Transduction Laboratories, Lexington, KY), was used for immunoprecipitation of tyrosine-phosphorylated proteins and for Western blot to detect tyrosinephosphorylated proteins in 4G10 inmunoprecipitates. Immunoprecipitated tyrosine-phosphorylated proteins were characterized further by alkaline phosphatase treatment $\left(2 \mathrm{U} / 50 \mu \mathrm{l}, 16 \mathrm{hr}, 37^{\circ} \mathrm{C}\right.$; New England BioLabs, Beverly, MA). Two rabbit polyclonal antisera raised against MalE fusion proteins (New England BioLabs) containing sequences specific to Kv1.3 were generously provided by Dr. James Douglass (Cai and Douglass, 1993). Both antisera were used for Western blotting and immunoprecipitation. EGFr expression was detected with a human-specific mouse monoclonal antibody (E12020, Transduction Laboratories). src expression ( $\mathrm{v}$-src and c-src) was detected with a mouse monoclonal antibody (MAb327, Oncogene Science, Cambridge, MA). All other chemicals used for Western blotting, immunoprecipitation, and electrophysiology were purchased from Sigma (St. Louis, MO).

Patch-clamp recording. Macroscopic currents in cell-attached membrane patches were recorded $24-72 \mathrm{hr}$ after transfection using an Axopatch-1B amplifier (Axon Instruments, Foster City, CA). Cells were visualized at $40 \times$ magnification using a phase-contrast water immersion lens (Zeiss, Thornwood, NY). The bath solution consisted of (in mM): 150 $\mathrm{KCl}, 10 \mathrm{HEPES}, 1 \mathrm{EGTA}$, and $0.5 \mathrm{MgCl}_{2}, \mathrm{pH} 7.5$. The pipette solution consisted of (in $\mathrm{mM}$ ): $30 \mathrm{KCl}, 70 \mathrm{NaCl}, 2 \mathrm{CaCl}_{2}, 1 \mathrm{EGTA}$, and $10 \mathrm{HEPES}$, $\mathrm{pH}$ 7.5. Electrodes were fabricated from Jencons glass (\#M15/10), firepolished to $\sim 1 \mu \mathrm{m}$, and coated near the tip with beeswax to reduce the capacitance of the glass. Pipette resistances were between 9 and $14 \mathrm{M} \Omega$. The effects of pervanadate were tested via application of the drug to the bath by direct pipetting into the recording chamber or by laminar flow perfusion. In addition, $\mathrm{Na}_{3} \mathrm{VO}_{4}$ was applied directly to the inside face of detached membrane patches to determine whether vanadate ion acts as a blocker of the Kv1.3 channel.

Cells were held at a command potential of $-80 \mathrm{mV}$ and stepped to a depolarizing potential of $+40 \mathrm{mV}$ for a pulse duration of $1000 \mathrm{msec}$. Voltage signals were generated and data were captured using a Microstar DAP $800 / 2$ board (Microstar Lab, Bellevue, WA). Cells were stimulated at $\geq 45 \mathrm{sec}$ intervals to prevent cumulative inactivation of the Kv1.3 channel (Marom et al., 1993). The amplifier output was filtered at $2 \mathrm{kHz}$, digitized at $2-5 \mathrm{kHz}$, and stored for later analysis. Data were analyzed using software written in our laboratory, in combination with the analysis packages Origin (MicroCal Software, Northampton, MA) and Quattro Pro (Borland International, Scotts Valley, CA). Data traces were linearly subtracted for leakage conductance. Initial peak current was taken $\sim 5$ min after achieving the cell-attached configuration (defined as time -5), and pervanadate was added at time 0 . The inactivation of the macroscopic current was fit to the sum of two exponentials by minimizing the sums of squares. The two inactivation time constants were combined by multiplying each by its weight and summing as described previously (Kupper et al., 1995). Statistical significance was defined at $p \leq 0.05$.

\section{RESULTS}

\section{Transfected HEK 293 cells express Kv1.3}

The mammalian cell line HEK 293 is used widely for the expression of cloned channels, because this line expresses few endogenous channels and expresses high levels of cloned proteins (Marshall et al., 1995). Kv1.3 channel protein expression in lipofectamine-transfected HEK 293 cells is demonstrated by SDS-PAGE Western blot (Fig. 
A

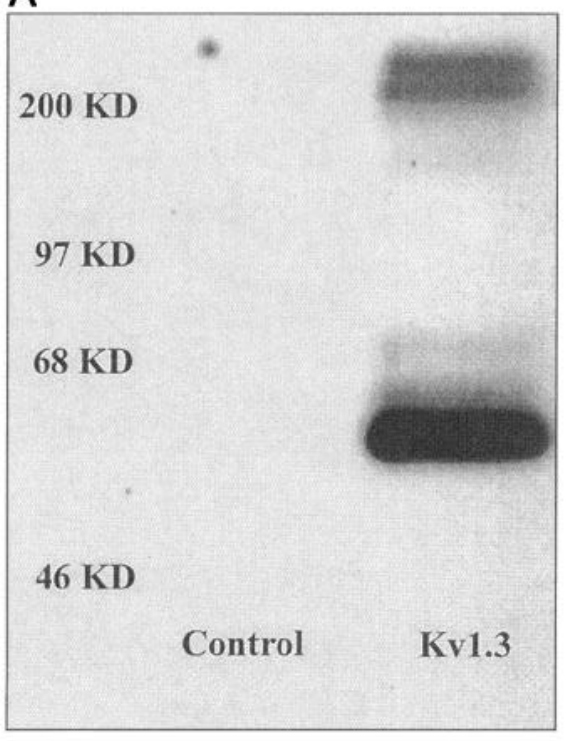

B

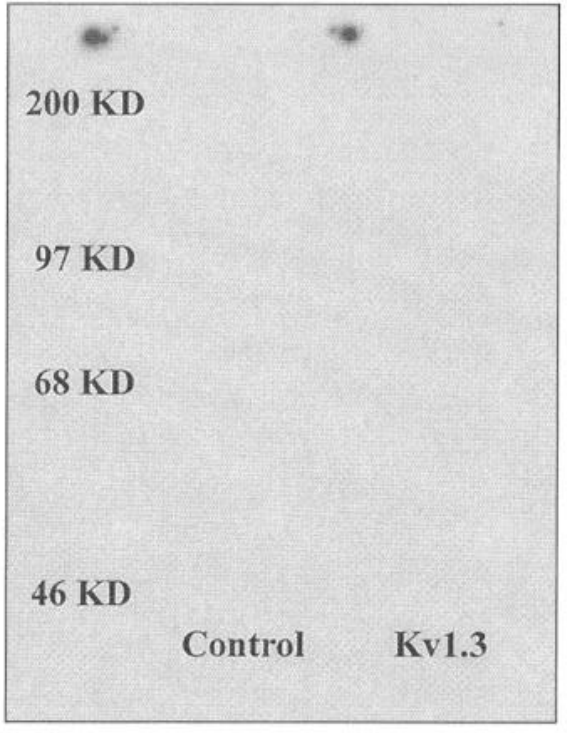

Figure 1. Western blot to demonstrate expression of Kv1.3 in transfected HEK 293 cells. Cells were transfected with cDNA for either control vector or Kv1.3. Triton X-100-soluble cell lysates were prepared $2 \mathrm{~d}$ after transfection, and the lysate proteins were separated by SDS-PAGE and electrotransferred to nitrocellulose. Immunoblots were incubated with T4Kv1.3 polyclonal antiserum, which recognizes the $C$ terminus of $\operatorname{Kv1.3}(A)$, or with preimmune serum $(B)$. Primary antibody binding was visualized by incubation with a HRP-conjugated secondary antibody and ECL autoradiography.
1A) using a polyclonal antiserum (Cai and Douglass, 1993) that recognizes residues $478-523$ of $\mathrm{Kv} 1.3$. The channel is not detected by the preimmune serum (Fig. $1 B$ ). The electrophoretic mobility of $\mathrm{Kv} 1.3$ is in agreement with the predicted $M_{\mathrm{r}}$ of the channel $(58 \mathrm{kDa})$ and its post-translationally modified forms (Swanson et al., 1990; Cai and Douglass, 1993). The 58-75 kDa Kv1.3 immunoreactivity is seen only in immunoblots prepared from Kv1.3-transfected cells (Fig. $1 A)$. The band-shift of proteins, as shown by decreased electrophoretic mobility on SDS-PAGE, is an index of protein phosphorylation (Shi et al., 1994; White and Kahn, 1994). Thus, the bands above $58 \mathrm{kDa}$ are probably attributable to phosphorylation and/or glycosylation of the channel (Cai and Douglass, 1993; Strong et al., 1995). These biochemical characteristics of Kv1.3 expressed in transfected HEK 293 cells are similar to those of native Kv1.3 in T lymphocytes (Cai and Douglass, 1993). Kv1.3 protein expression is detected at $1 \mathrm{~d}$ after transfection, and maximal Kv1.3 expression occurs $2 \mathrm{~d}$ after transfection (data not shown). The maximal expression of Kv1.3 protein coincides with the peak of functional expression, as measured in Kv1.3-transfected HEK 293 cells by patch-clamp analysis (Bowlby and Levitan, 1995).

Higher $M_{\mathrm{r}} \mathrm{Kv} 1.3$ immunoreactivity (HMW Kv1.3i; $200 \mathrm{kDa}$ ) is also detected in immunoblots prepared from Kv1.3-transfected lysates (Fig. 1A). A greater proportion of HMW Kv1.3i compared with $58-77 \mathrm{kDa} \mathrm{Kv} 1.3$ immunoreactivity is detected in the Triton $\mathrm{X}$-100-insoluble pellet compared with the clarified lysate fraction. The appearance of HMW Kv1.3i is not affected by freezing or heat treatment of the sample (data not shown).

\section{Tyrosine phosphorylation of Kv1.3 increases when the channel is coexpressed with the constitutively active tyrosine kinase v-src}

The nonreceptor tyrosine kinase v-src lacks the C-terminal regulatory domain found in cellular src kinases and, thus, v-src is constitutively active (Maroney et al., 1992). HEK 293 cells were transfected with control vector, vector containing Kv1.3 or v-src DNA, or the Kv1.3 and v-src vectors together (cotransfection). Cells were harvested $2 \mathrm{~d}$ after transfection. $\mathrm{v}$-src kinase expression was verified by Western blot analysis using an antibody that specifically recognizes src kinase (data not shown). Additionally, these experiments revealed that HEK 293 cells express low levels of endogenous src kinases (data not shown). The expression of
Kv1.3 was verified by Western blot analysis of cell lysates with the anti-Kv1.3 antibody (as in Fig. $1 \mathrm{~A}$ ) in all experiments. Coexpression of Kv1.3 and v-src $(K v 1.3+v$-src) does not affect Kv1.3 protein expression. Furthermore, coexpression of Kv1.3 and v-src does not affect v-src expression.

Tyrosine-phosphorylated proteins were immunoprecipitated from HEK 293 cell lysates with an anti-phosphotyrosine antibody (Wang, 1988) and were separated by SDS-PAGE followed by Western blot probed with anti-Kv1.3 antibody. Kv1.3 exhibits low basal levels of tyrosine phosphorylation (Fig. $2 A$ ), but its tyrosine phosphorylation increases dramatically when it is coexpressed with v-src (Fig. 2A). Similar results are obtained by a complementary approach, immunoprecipitation with a polyclonal antiserum that recognizes the C-terminal domain of Kv1.3, followed by Western blot analysis using an anti-phosphotyrosine antibody (data not shown).

The increase in Kv1.3 tyrosine phosphorylation is also associated with an increase in the $M_{\mathrm{r}}$ of Kv1.3 (Fig. $2 A$ ). Under basal conditions, the predominant Kv1.3 band in cell lysates has an $M_{\mathrm{r}}$ of $58 \mathrm{kDa}$ (Fig. 1A). In contrast, the $M_{\mathrm{r}}$ of tyrosine-phosphorylated $\mathrm{Kv} 1.3$ is 77 $\mathrm{kDa}(K v 1.3+v$-src in Fig. $2 A)$. This Kv1.3 band-shift is reversible by treatment of anti-phosphotyrosine immunoprecipitates with alkaline phosphatase ( $2 \mathrm{U} / 50 \mu \mathrm{l}$; Fig. $2 B$ ). The $M_{\mathrm{r}}$ of $\mathrm{Kv} 1.3$ is again $58 \mathrm{kDa}$ after phosphatase treatment. Alkaline phosphatase treatment effectively removes all phosphate from the immunoprecipitate protein tyrosine residues, as measured by Western blot analysis using the anti-phosphotyrosine antibody PY20 (data not shown).

Kv1.3 tyrosine phosphorylation was quantified by scanning ECL autoradiograms with a densitometer. Background-subtracted density was integrated over the range of Kv1.3 immunoreactivity from 58 to $79 \mathrm{kDa}$. The basal value of Kv1.3 tyrosine phosphorylation, which presumably reflects the activity of endogenous tyrosine kinases, was assigned an arbitrary value of one. This value was used as a normalization factor for all other transfection/expression conditions. Tyrosine phosphorylation of Kv1.3 increases by a factor of eight when the channel is coexpressed with v-src, as compared with the basal phosphorylation level of the channel (Fig. 2C).

\section{Kv1.3 tyrosine phosphorylation increases when the channel is coexpressed with the EGFr tyrosine kinase}

The EGFr tyrosine kinase dimerizes, autophosphorylates, and phosphorylates substrate proteins after the binding of EGF (Ca- 
A

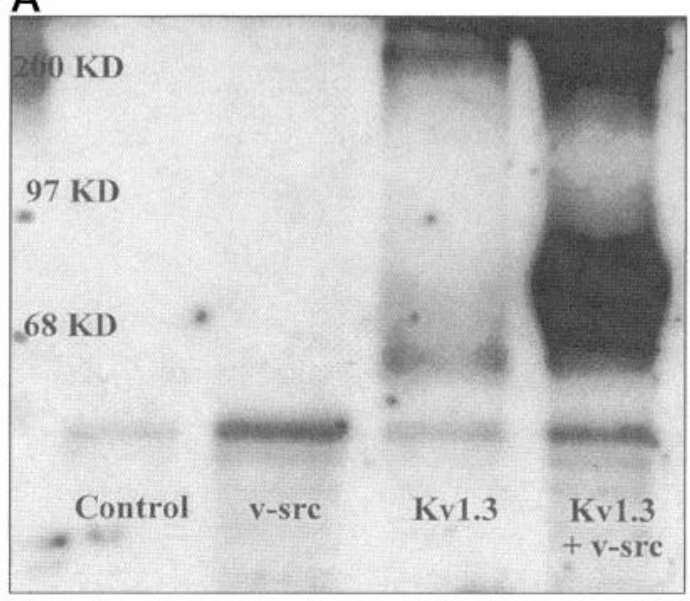

B

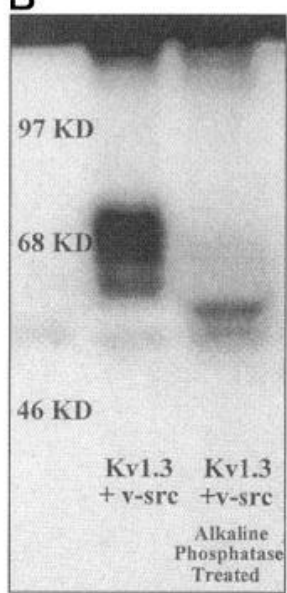

Figure 2. Kv1.3 tyrosine phosphorylation is increased in v-src-cotransfected cells. HEK 293 cells were transfected with control vector (Control), v-src, Kv1.3, or Kv1.3 together with v-src $(K v 1.3+v$-src $)$. Two days after transfection, Triton X-100-soluble cell lysates were prepared and tyrosine-phosphorylated proteins were immunoprecipitated with the anti-phosphotyrosine antibody 4G10. The immunoprecipitated proteins were separated by SDSPAGE, transferred to nitrocellulose, and probed with antiKv1.3 antiserum. Note the artifactual band at $\sim 50 \mathrm{kDa}$ in all lanes of this and subsequent figures. $A$, v-src cotransfection increases the amount of tyrosine-phosphorylated $\mathrm{Kv} 1.3$ and its $M_{\mathrm{r}}$. B, The v-src-induced increase in Kv1.3 tyrosine phosphorylation and the band-shift in its $M_{\mathrm{r}}$ are reversed after alkaline phosphatase treatment of the immunoprecipitate. $C$, Tyrosine phosphorylation of Kv1.3, as measured by quantitative immunodensitometry, increases in v-src-cotransfected cells $(n=10)$.

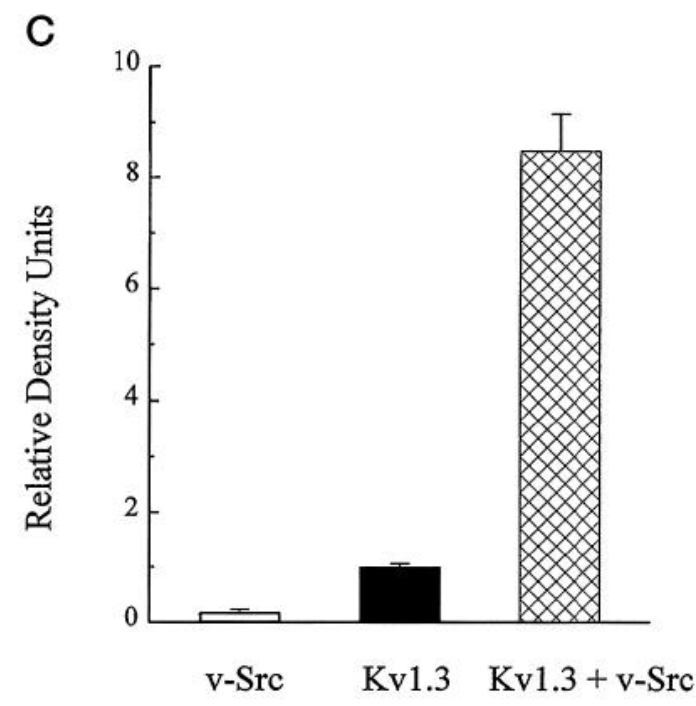

dena and Gill, 1992). Additionally, the ligand-bound EGFr regulates downstream Ser/Thr kinases via phospholipase $\mathrm{C}$ activation (Cadena and Gill, 1992). HEK 293 cells were transfected with control vector, vector containing Kv1.3 or EGFr, or the Kv1.3 and EGFr vectors together (cotransfection). Cells were harvested $2 \mathrm{~d}$ after transfection. Kv1.3 expression was verified in all experiments. EGFr expression was verified by Western blot analysis using a specific monoclonal antibody that recognizes EGFr; Kv1.3 coexpression does not affect EGFr protein expression. Modest levels of EGFr immunoreactivity were also detected in lysates prepared from control and Kv1.3-transfected cells, indicating that HEK 293 cells endogenously express EGFr (data not shown).

$\mathrm{Kv} 1.3$ tyrosine phosphorylation was determined by immunoprecipitation and Western blot analysis as described above. Kv1.3 tyrosine phosphorylation increases in Kv1.3- and EGFrcotransfected cells compared with basal Kv1.3 tyrosine phosphorylation (Fig. 3A). Additionally, Kv1.3 has a higher $M_{\mathrm{r}}$ when coexpressed with the EGFr. The relative increase in Kv1.3 tyrosine phosphorylation after Kv1.3 and EGFr coexpression is approximately fourfold, as determined by densitometry (Fig. 3B). EGF treatment $(10 \mathrm{ng} / \mathrm{ml}$ medium, $60 \mathrm{~min})$ of cotransfected cells does not enhance Kv1.3 tyrosine phosphorylation any further, indicating that autocrine or serum levels of EGF are sufficient for the activation of EGFr. Substantial EGFr autophosphorylation in EGFr-transfected cells was detected by Western blot analysis of lysate proteins using anti-phosphotyrosine and anti-EGFr antibodies, suggesting the presence of EGF in the cell culture medium (data not shown).

\section{Kv1.3 is tyrosine-phosphorylated by endogenous kinases after treatment of cells with the membrane- permeant tyrosine phosphatase inhibitor pervanadate}

Cellular phosphotyrosine levels increase after treatment with micromolar levels of pervanadate. Pervanadate inhibits tyrosine phosphatases; in contrast, Ser/Thr phosphatases are unaffected by submillimolar doses of pervanadate (Hunter, 1995; Wallace, 1995). Pervanadate treatment increases the $M_{\mathrm{r}}$ of Kv1.3 as detected in immunoblots of cell lysates (Fig. 4A). Kv1.3 immunoreactivity on Western blots is found predominantly at $58 \mathrm{kDa}$ in lysates prepared from unstimulated Kv1.3-transfected cells, and the pervanadate-induced band-shift reflects a large redistribution of the total channel immunoreactivity from 58 to $65 \mathrm{kDa}$ (Fig. $4 B$ ).

In addition to this band-shift, pervanadate treatment $(250 \mu \mathrm{M}$, $60 \mathrm{~min}$ ) induces robust Kv1.3 tyrosine phosphorylation, as shown by anti-phosphotyrosine immunoreactivity of anti-Kv1.3 immunoprecipitates on Western blots (Fig. $5 A, B$ ). An identical result is 
A

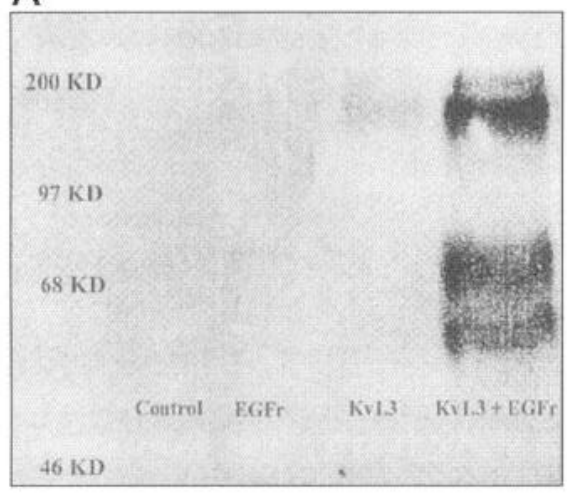

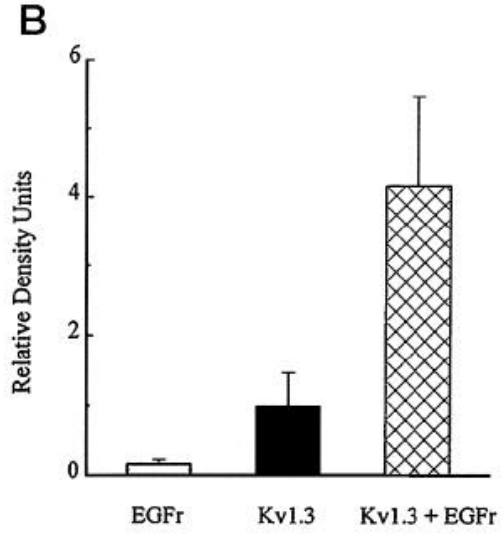

Figure 3. Kv1.3 tyrosine phosphorylation is increased in cells cotransfected with an EGFr kinase. HEK 293 cells were transfected with control vector, EGFr, Kv1.3, or Kv1.3 together with EGFr $(K v 1.3+E G F r)$. Two days after transfection, Triton X-100-soluble cell lysates were prepared and tyrosine-phosphorylated proteins were immunoprecipitated with the antibody 4G10. The immunoprecipitated proteins were separated by SDS-PAGE, transferred to nitrocellulose, and probed with anti$\mathrm{Kv} 1.3$ antiserum. $A$, EGFr cotransfection increases Kv1.3 phosphotyrosine immunodensity. $B$, Tyrosine phosphorylation of Kv1.3, as measured by quantitative immunodensitometry, increases in EGFrcotransfected cells $(n=4)$. obtained by immunoprecipitation with an antiserum directed against the intracellular C-terminal region of Kv1.3 (Fig. $5 A$ ), or by immunoprecipitation using an antiserum directed against the extracellular region $\mathrm{S} 1 / \mathrm{S} 2$ of $\mathrm{Kv} 1.3$ (Fig. $5 B$ ), followed by Western blot with anti-phosphotyrosine antibody. Similar results are obtained when tyrosine-phosphorylated proteins are first immunoprecipitated with an anti-phosphotyrosine antibody, followed by Western blotting using an anti-Kv1.3 antibody (Fig. 5C). Quantitative densitometric analysis of anti-phosphotyrosineimmunoprecipitated Kv1.3 shows a low level of Kv1.3 basal tyrosine phosphorylation, and a large increase in the level of Kv1.3 tyrosine phosphorylation after pervanadate treatment (Fig. $5 D$ ). The $M_{\mathrm{r}}$ of the predominant band of immunoprecipitated, tyrosine-phosphorylated Kv1.3 after pervanadate treatment is 65 $\mathrm{kDa}$, as shown for all three immunoprecipitation-Western blot strategies described above (Fig. $5 A-C$ ). This is in agreement with the band-shift described in Figure 4.

The increase in Kv1.3 tyrosine phosphorylation after pervanadate treatment is dose-dependent (Fig. 6). Control and Kv1.3expressing cells were treated with $0,25,100$, and $250 \mu \mathrm{M}$ pervanadate for $60 \mathrm{~min}$. Tyrosine-phosphorylated proteins were immunoprecipitated and separated by SDS-PAGE and probed with anti-Kv1.3 antiserum (Fig. 6A). Quantitative immunodensitometry analysis indicates that as little as $25 \mu \mathrm{M}$ pervanadate increases Kv1.3 tyrosine phosphorylation compared with basal values (Fig. 6B). Kv1.3 tyrosine phosphorylation reaches maximal levels at a pervanadate concentration of $100 \mu \mathrm{M}$ (Fig. $6 B$ ).

Pervanadate increases cellular phosphotyrosine levels in a timedependent manner (Bourgoin and Grinstein, 1992; Zor et al., 1993; Wallace, 1995). The time course of Kv1.3 tyrosine phosphorylation after pervanadate treatment was determined in control and Kv1.3-expressing cells (Fig. 7). Cells were treated with $250 \mu \mathrm{M}$ pervanadate for 0,20 , and $60 \mathrm{~min}$. Tyrosinephosphorylated proteins were immunoprecipitated, separated by SDS-PAGE, and probed with anti-Kv1.3 antiserum (Fig. 7A). Kv1.3 tyrosine phosphorylation increases compared with basal level after pervanadate treatment for 20 and $60 \mathrm{~min}$, as shown by quantitative immunodensitometry analysis (Fig. $7 B$ ).

The presence of basal Kv1.3 tyrosine phosphorylation, as well as the large increase in Kv1.3 tyrosine phosphorylation after pervanadate treatment, indicates that endogenous tyrosine kinases and phosphatases in HEK 293 cells recognize Kv1.3 as a substrate. The magnitude of increased Kv1.3 tyrosine phosphorylation after pervanadate treatment reveals the presence of a substantial tyrosine phosphorylation/dephosphorylation cycle for Kv1.3 in these cells.

\section{Kv1.3 activity is suppressed after treatment of cells with pervanadate}

To determine whether a treatment that increases Kv1.3 tyrosine phosphorylation influences channel activity, we measured the effects of pervanadate treatment on Kv1.3 macroscopic currents in cell-attached membrane patches. HEK 293 cells were transfected with vector containing Kv1.3 DNA. Pervanadate treatment $\left(\mathrm{Na}_{3} \mathrm{VO}_{4}+\mathrm{H}_{2} \mathrm{O}_{2}+\right.$ catalase, $\left.20 \mathrm{~min}\right)$ causes a clear suppression of Kv1.3 current (Fig. 8A) compared with control treatment $\left(\mathrm{H}_{2} \mathrm{O}_{2}+\right.$ catalase, $\left.20 \mathrm{~min}\right)$. The pervanadate-induced suppression of Kv1.3 current is time-dependent and occurs within 2 min of application of the drug; it reaches half-suppression of the initial current at $\sim 10 \mathrm{~min}$ (Fig. $8 B$ ). Although pervanadate treatment causes a significant decrease in Kv1.3 peak current (Fig. 8A,C), there is no significant change in the rate of inactivation of Kv1.3 (Fig. $8 A, D$ ). Furthermore, pervanadate has no effect on nontransfected cells, and the current-voltage relationship for the peak Kv1.3 current is the same in the absence and presence of pervanadate (data not shown); thus, it is extremely unlikely that pervanadate is activating an opposing inward current. Finally, vanadate ion does not appear to act as a blocker of Kv1.3, because vanadate application to the cytoplasmic side of the membrane does not affect Kv1.3 currents recorded from cell-free inside-out membrane patches (data not shown).

\section{Pervanadate-induced tyrosine phosphorylation and suppression of current are reduced in the mutant Y449F Kv1.3}

The substrate sequence flanking phosphorylated tyrosine residues contributes to kinase recognition (White and Kahn, 1994; Songyang et al., 1995). Acidic amino acids surrounding the phosphorylated tyrosine are found in many tyrosine kinase consensus motifs (Songyang et al., 1995), and additional kinase selectivity is conferred by flanking hydrophobic residues (Pawson, 1995; Songyang et al., 1995). Sequence analysis of Kv1.3 reveals the presence of potential tyrosine phosphorylation sites. Among these is $\mathrm{Tyr}^{449}$ in the putative C-terminal domain of $\mathrm{Kv} 1.3$, which is preceded by Glu residues at positions $-4,-5$, and -7 and is followed by Met at +1 and $\mathrm{Val}$ at +3 .

A mutant Kv1.3 channel was constructed by PCR mutagenesis, altering $\mathrm{Tyr}^{449}$ to $\mathrm{Phe}^{449}$ (Y449F Kv1.3). Kv1.3 and Y449F Kv1.3 protein expression in HEK 293 cells are identical (measured by Western blot as in Fig. 1) (data not shown). The effects of pervanadate treatment on $\mathrm{Y} 449 \mathrm{~F} \mathrm{Kv} 1.3$ macroscopic currents were measured in cell-attached membrane patches using the same protocol as for Kv1.3 in Figure 8. In contrast to the pervanadate- 

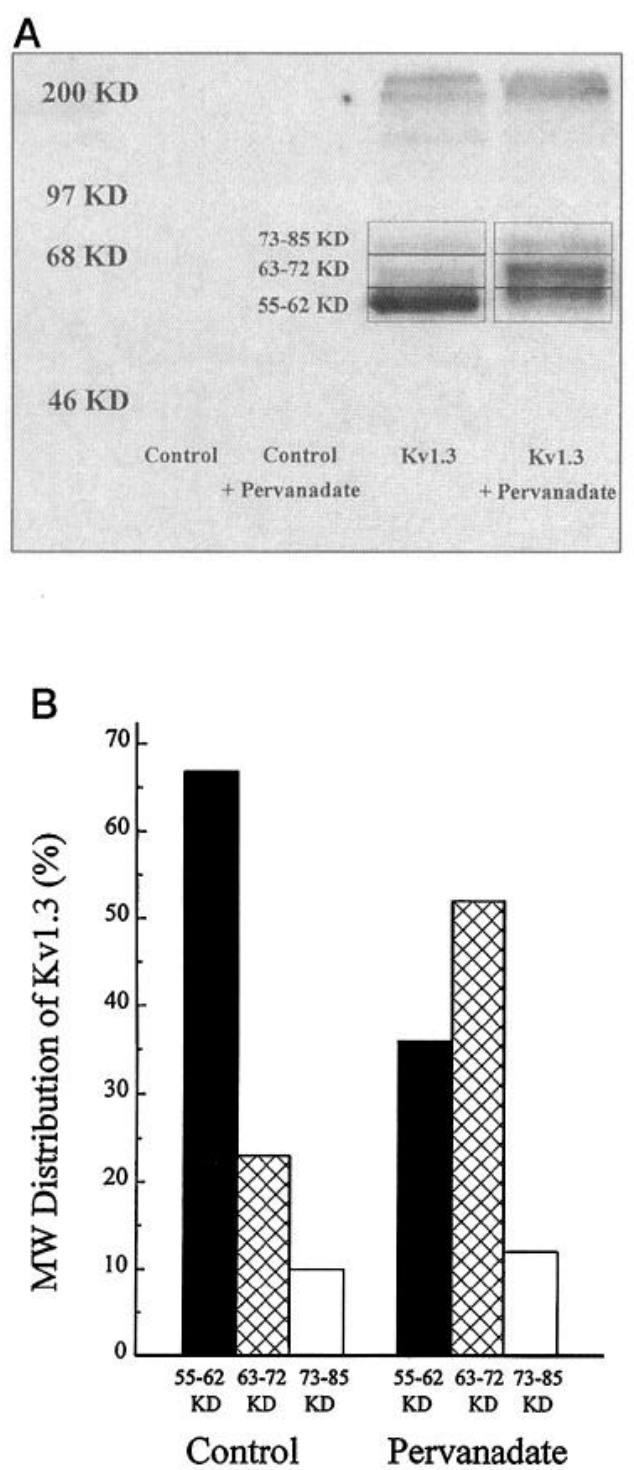

Figure 4. The $M_{\mathrm{r}}$ of Kv1.3 is increased by pervanadate treatment. HEK 293 cells were transfected with control vector or Kv1.3. Two days after transfection, cells were treated with the membrane-permeant tyrosine phosphatase inhibitor pervanadate $(250 \mu \mathrm{M}, 60 \mathrm{~min})$. A, Triton X-100soluble cell lysates were prepared, and total lysate proteins were separated by SDS-PAGE, transferred to nitrocellulose, and probed with anti-Kv1.3 antiserum. The boxes in $A$ define the areas that were integrated to generate the quantitative immunodensity data in $B . B$, The distribution of Kv1.3 immunoreactivity shifts to higher $M_{\mathrm{r}}$ bands after pervanadate treatment $(n=4)$.

induced suppression of Kv1.3 current (Fig. $8 A-C$ ), pervanadate fails to suppress Y449F Kv1.3 current (Fig. 9A,B). These results indicate that phosphorylation of $\mathrm{Tyr}^{449}$ by endogenous tyrosine kinase(s) is responsible for the pervanadate suppression of Kv1.3 current. The tyrosine phosphorylation of $\mathrm{Y} 449 \mathrm{~F} \mathrm{Kv} 1.3$, induced by pervanadate treatment $(250 \mu \mathrm{M}, 60 \mathrm{~min})$, is markedly lower than that of Kv1.3 (Fig. 9C,D). Thus, Kv1.3 is phosphorylated on $\mathrm{Tyr}^{449}$ by endogenous tyrosine kinase(s), and in fact $\mathrm{Tyr}^{449}$ is a major target for this (these) kinase(s). However, there is some residual phosphotyrosine signal in Y449F Kv1.3 (Fig. 9C,D), indicating that $\mathrm{Kv} 1.3$ is phosphorylated on other tyrosine residues in addition to Y449.
A

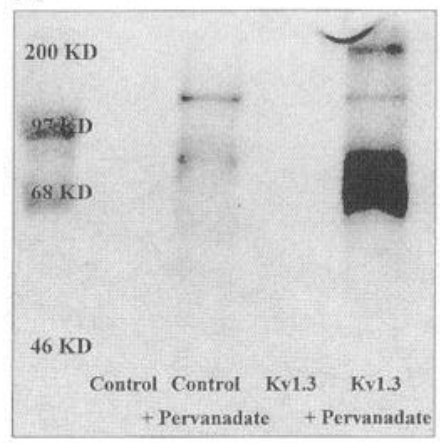

C

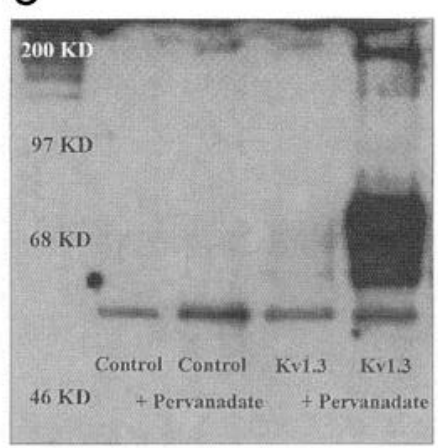

B

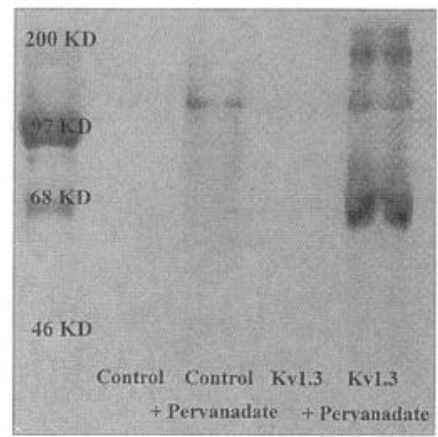

D

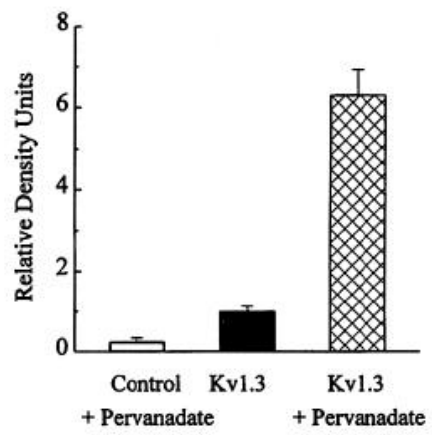

Figure 5. Pervanadate treatment increases tyrosine phosphorylation of Kv1.3. Tyrosine phosphorylation of Kv1.3 after pervanadate treatment $(250 \mu \mathrm{M}, 60 \mathrm{~min})$ is detected by immunoprecipitation with $\mathrm{Kv} 1.3$ antiserum that binds to the $\mathrm{Kv} 1.3 \mathrm{C}$-terminal domain $(A)$ or to the $\mathrm{Kv} 1.3$ extracellular S1-S2 loop domain $(B)$, followed by Western blot with anti-phosphotyrosine antibody. $C$, Tyrosine phosphorylation of Kv1.3 is demonstrated by immunoprecipitation of tyrosine-phosphorylated proteins with antibody $4 \mathrm{G} 10$, followed by Western blot with anti-Kv1.3 antiserum. $D$, Tyrosine phosphorylation of Kv1.3, as measured by quantitative immunodensitometry, increases in pervanadate-treated cells $(n=$ 12). Experimental protocol as for $C$.

\section{DISCUSSION}

The present findings provide strong evidence that protein tyrosine kinases and phosphatases regulate the phosphorylation and activity of Kv1.3. The control of membrane potential by protein tyrosine kinases and phosphatases is of considerable interest because most studies of phosphotyrosine-signaling pathways have focused on cellular differentiation and growth (Hunter, 1995). It is particularly intriguing that postmitotic neurons express extremely high levels of protein tyrosine kinases (Brugge et al., 1985; Hanley, 1988), and yet the signaling functions of these kinases in neurons remain largely unexplored.

\section{Tyrosine phosphorylation of Kv1.3 after coexpression with tyrosine kinases}

Coexpression of the nonreceptor tyrosine kinase v-src, or the receptor tyrosine kinase EGFr, robustly increases Kv1.3 tyrosine phosphorylation. The magnitude of Kv1.3 phosphotyrosine immunodensity after EGFr coexpression is approximately half of that seen after v-src cotransfection. Sequence analysis of Kv1.3 suggests that there are tyrosine residues at which v-src and the activated EGFr kinases may directly phosphorylate the channel, although this has not yet been demonstrated conclusively. Alternatively, coexpressed tyrosine kinases could contribute indirectly to the phosphorylation of Kv1.3 by activating a downstream en- 
A

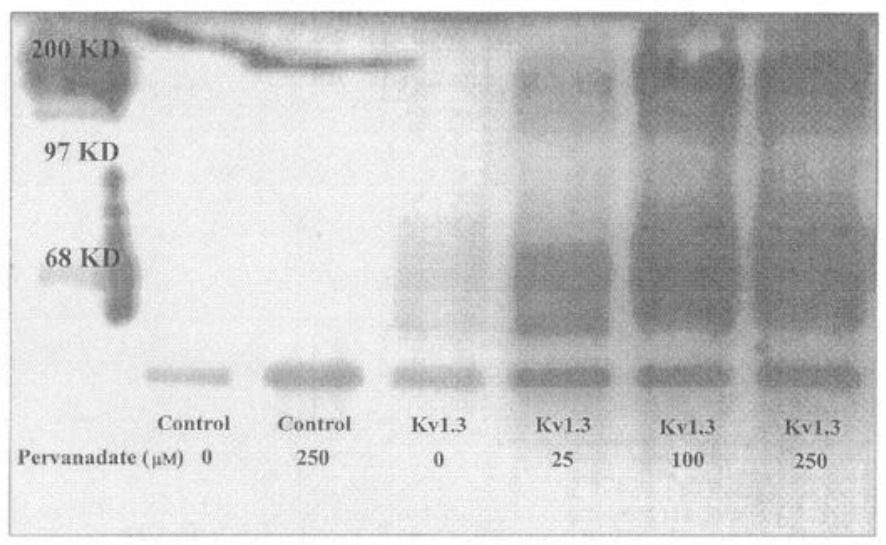

B

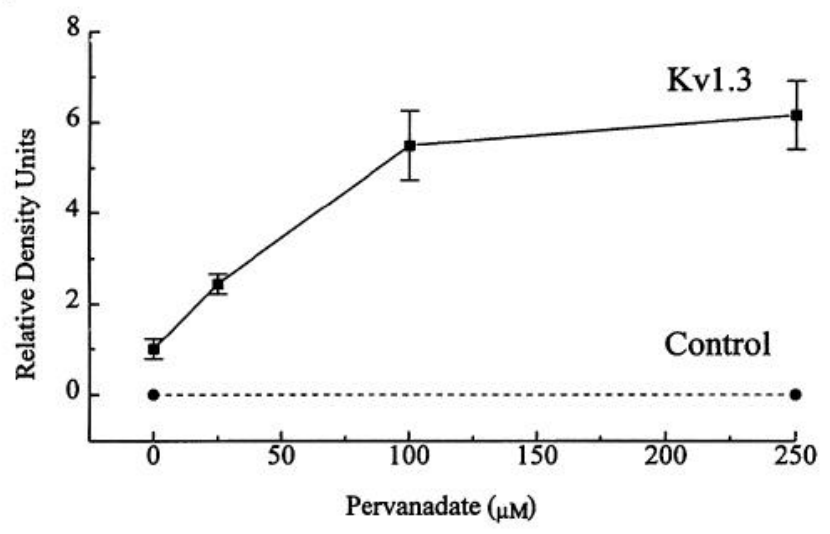

Figure 6. The effect of pervanadate concentration on Kv1.3 tyrosine phosphorylation. HEK 293 cells were transfected with control vector or $\mathrm{Kv1.3}$. Two days after transfection, cells were treated with pervanadate $(60$ min; $0,25,100$, or $250 \mu \mathrm{M})$. Triton X-100-soluble cell lysates were prepared, and tyrosine-phosphorylated proteins were immunoprecipitated with antibody $4 \mathrm{G} 10$. $A$, The immunoprecipitated proteins were separated by SDS-PAGE, transferred to nitrocellulose, and probed with anti-Kv1.3 antiserum. $B$, Tyrosine phosphorylation of Kv1.3, as measured by quantitative immunodensitometry, increases in a concentration-dependent manner after pervanadate treatment $(n=3)$.

dogenous tyrosine kinase (or multiple kinases) that recognizes Kv1.3. Such ion channel phosphorylation by interacting signal transduction pathways has been demonstrated previously. The $\mathrm{Kv} 1.2$ channel is phosphorylated by a downstream endogenous tyrosine kinase after carbachol treatment of HEK 293 cells, in which channel and $\mathrm{m} 1$ muscarinic receptors have been coexpressed (Huang et al., 1993). Alternatively, tyrosine kinases may activate Ser/Thr kinases (Cadena and Gill, 1992). The activation of platelet-derived growth factor and fibroblast growth factor receptor tyrosine kinases modulates Kv1.5 current amplitude by increasing phospholipase $\mathrm{C}$ and protein kinase $\mathrm{C}$ activity (Timpe and Fantl, 1994). Thus, caution should be taken in interpreting whether coexpressed kinases directly phosphorylate ion channels, because of cross-talk between signal transduction pathways.

\section{Tyrosine phosphorylation of Kv1.3 by endogenous kinases}

The combination of biochemical and patch-clamp analysis reveals that Kv1.3 is tyrosine-phosphorylated and functionally suppressed by endogenous tyrosine kinases in HEK 293 cells. Basal tyrosine

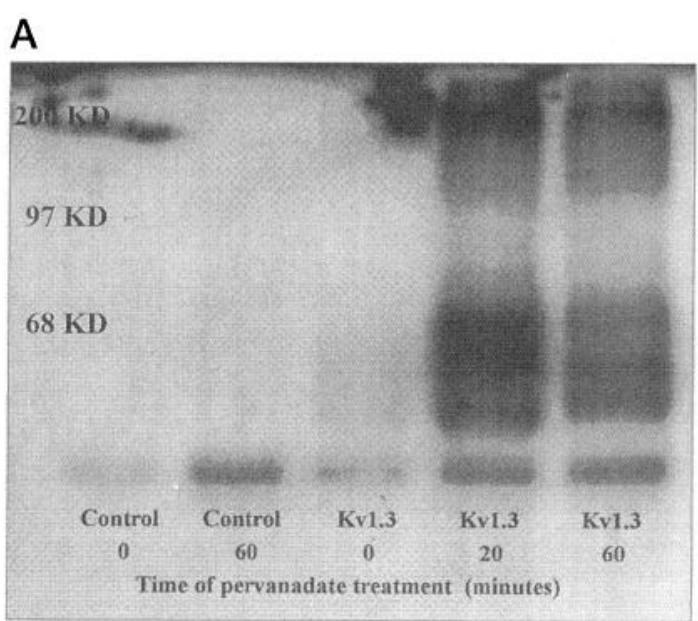

B

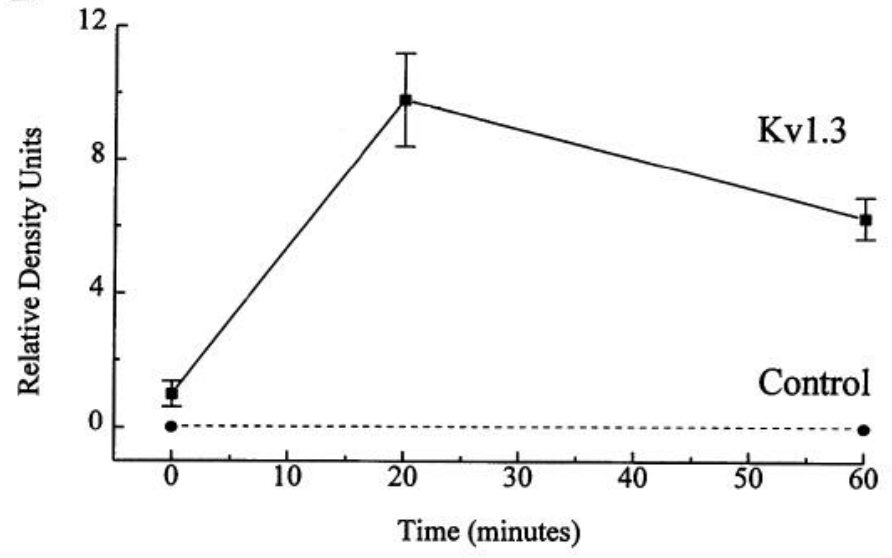

Figure 7. Time course of pervanadate effect on Kv1.3 tyrosine phosphorylation. HEK 293 cells were transfected with control vector or Kv1.3. Two days after transfection, cells were treated with pervanadate $(250 \mu \mathrm{M} ; 0,20$, or $60 \mathrm{~min}$ ). Triton X-100-soluble cell lysates were prepared, and tyrosinephosphorylated proteins were immunoprecipitated with antibody 4G10.A, The immunoprecipitated proteins were separated by SDS-PAGE, transferred to nitrocellulose, and probed with anti-Kv1.3 antiserum. $B$, The time course of pervanadate effect on tyrosine phosphorylation of Kv1.3, as measured by quantitative immunodensitometry $(n=3)$.

phosphorylation of Kv1.3 is consistently detected, indicating that there are constitutively active tyrosine kinases that recognize and phosphorylate Kv1.3. The phosphorylation of Kv1.3 increases in a time- and dose-dependent manner after treatment with pervanadate. Thus, tyrosine phosphorylation of Kv1.3 occurs in cells that express normal levels of tyrosine kinases. $\mathrm{Tyr}^{449}$ appears to be a major target for endogenous tyrosine kinases. However, there is residual tyrosine phosphorylation of the Y449F Kv1.3 mutant channel after pervanadate treatment and, thus, endogenous tyrosine kinases must also target other sites in Kv1.3.

Most studies indicate that tyrosine phosphatase inhibition (as opposed to tyrosine kinase activation) is the predominant effect of pervanadate (Hunter, 1995). Thus, the time- and dose-dependent accumulation of tyrosine-phosphorylated Kv1.3 after pervanadate treatment is probably attributable to the inhibition of endogenous protein tyrosine phosphatases, which participate in an ongoing tyrosine dephosphorylation-phosphorylation cycle of the channel. A minor component of increased Kv1.3 tyrosine phosphorylation may be attributable to pervanadate-induced activation of endog- 
C

Figure 8. Effect of pervanadate on Kv1.3 current. HEK 293 cells were transfected with $\mathrm{Kv} 1.3$, and cell-attached patch recordings were made $2 \mathrm{~d}$ later. $A$, Currents evoked by depolarizing voltage pulses, 20 min after treatment with $\mathrm{H}_{2} \mathrm{O}_{2}$ alone (Control) or with $100 \mu \mathrm{M}$ Pervanadate produced from $\mathrm{Na}_{3} \mathrm{VO}_{4}$ and $\mathrm{H}_{2} \mathrm{O}_{2}$. Both control and pervanadate cells also received catalase to quench the $\mathrm{H}_{2} \mathrm{O}_{2}$. B, Pervanadate suppresses Kv1.3 current in a time-dependent manner. Depolarizing pulses were administered $45 \mathrm{sec}$ apart (to avoid cumulative inactivation of $\mathrm{Kv} 1.3$ current), and the peak current evoked by each pulse $\left(I_{n}\right)$ is plotted relative to that evoked by the first pulse shown $\left(I_{-5}\right)$. The reagents were added at $n=0$. The negative pulse numbers refer to the baseline before the treatment. $C$, Peak current at time 0 (Control) was compared with that in the same cell after 20 min of Pervanadate treatment. Asterisk denotes significant difference at $p<0.05$ (Student's paired $t$ test; $n=9$ ). $D$, The normalized inactivation time constant of Kv1.3 current does not change after 20 min of Pervanadate treatment versus Control.
A

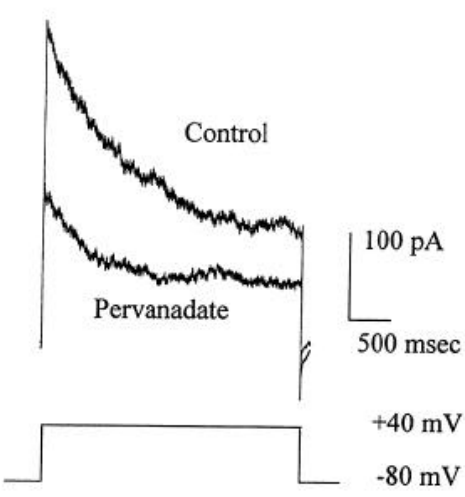

B

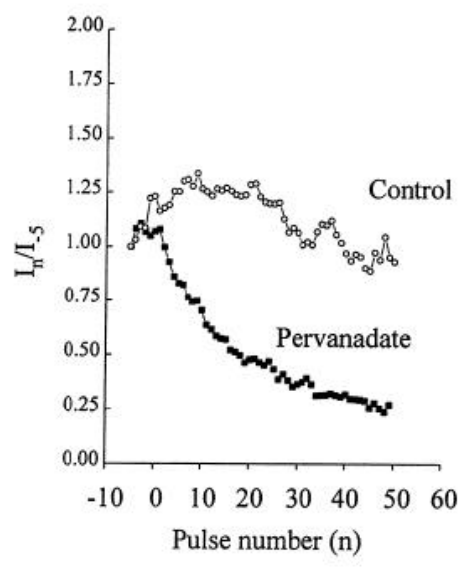

D

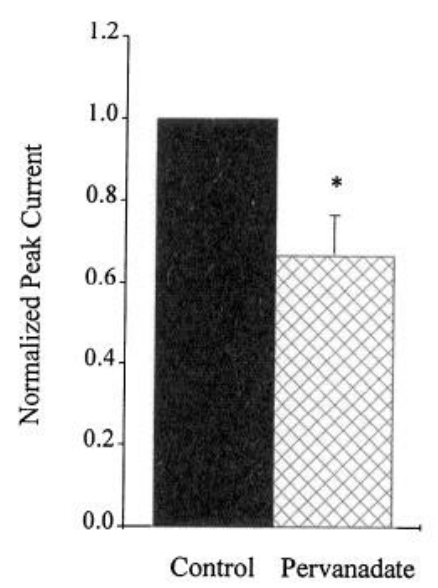

enous tyrosine kinases (Zor et al., 1993). However, other investigators have found no evidence for vanadate-induced activation of cellular tyrosine kinases (Grinstein et al., 1990). The endogenous tyrosine kinases that specifically phosphorylate Kv1.3 have not yet been identified, although HEK 293 cells express numerous nonreceptor and receptor kinases including several members of the src family, the EGFr, and the insulin receptor. The identification of neuronally expressed tyrosine kinases that phosphorylate Kv1.3 will be of particular interest.

\section{Functional effects of Kv1.3 tyrosine phosphorylation}

Pervanadate treatment suppresses Kv1.3 macroscopic currents in a time-dependent manner. The time courses of pervanadateinduced Kv1.3 tyrosine phosphorylation and current suppression are similar, suggesting a causal relationship between channel phosphorylation state and activity. Pervanadate-induced tyrosine phosphorylation of Kv1.3 decreases channel current, whereas channel inactivation is unchanged. In contrast, there is no suppression of current carried by the Y449F Kv1.3 mutant channel after pervanadate treatment. In addition, the extent of phosphorylation of Y449F Kv1.3 after pervanadate treatment is markedly less than that of Kv1.3. These results provide unequivocal evidence that the functional suppression is associated directly with the tyrosine phosphorylation of the channel protein.

There are several possible mechanisms for the pervanadateinduced suppression of Kv1.3 current. Tyrosine-phosphorylated
Kv1.3 may undergo conformational changes that decrease channel activity. Alternatively, tyrosine phosphorylation of Kv1.3 may lead to a decrease in the number of functional channels at the cell surface by the alteration of subunit assembly, targeting to the membrane, or sequestration of existing channels. The time course of pervanadate-induced tyrosine phosphorylation and suppression of Kv1.3 current is consistent with changes in the activity of existing channels. The protein levels of Kv1.3 do not change after pervanadate treatment and, thus, channel suppression does not appear to be mediated by changes in channel protein synthesis or degradation.

Several previous reports describe changes in ion channel activity after treatments that activate tyrosine kinases. $\mathrm{A} \mathrm{Ca}^{2+}$. activated $\mathrm{K}^{+}$channel opens in response to EGF in A431 and KB cells (Pandiella et al., 1989). Protein tyrosine phosphatase treatment increases the probability of the open state of a voltage-gated nonselective cation channel in Aplysia bag cell neurons (Wilson and Kaczmarek, 1993). Because this effect is observed in cell-free membrane patches, Wilson and Kaczmarek (1993) conclude that the cation channel activity is regulated by tyrosine phosphorylation of the channel or a closely associated protein. The most compelling evidence for direct regulation of $\mathrm{K}^{+}$channel activity by the phosphorylation of channel tyrosine residues was provided by Huang et al. (1993). Kv1.2 channel activity is markedly suppressed after carbachol activation of coexpressed $\mathrm{m} 1$ receptors. 
A

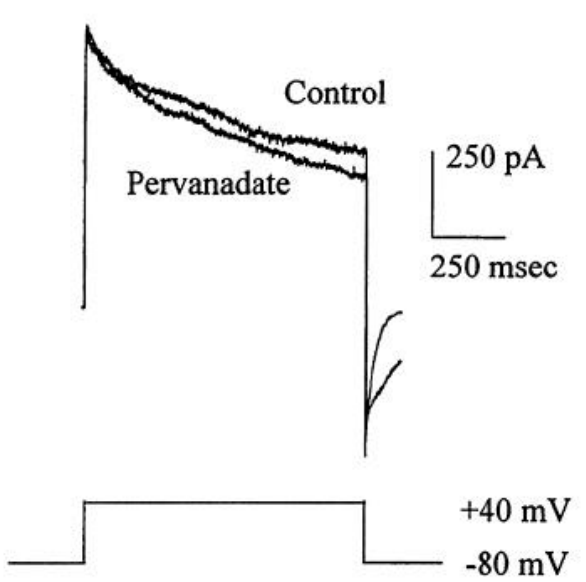

B

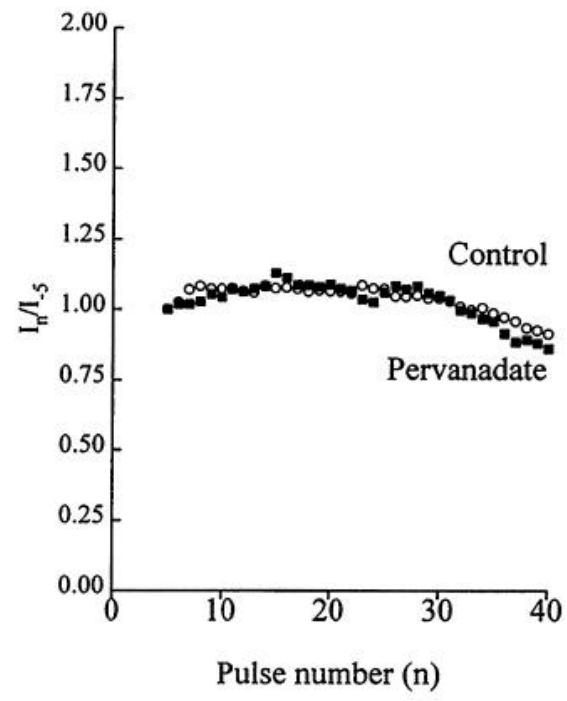

C

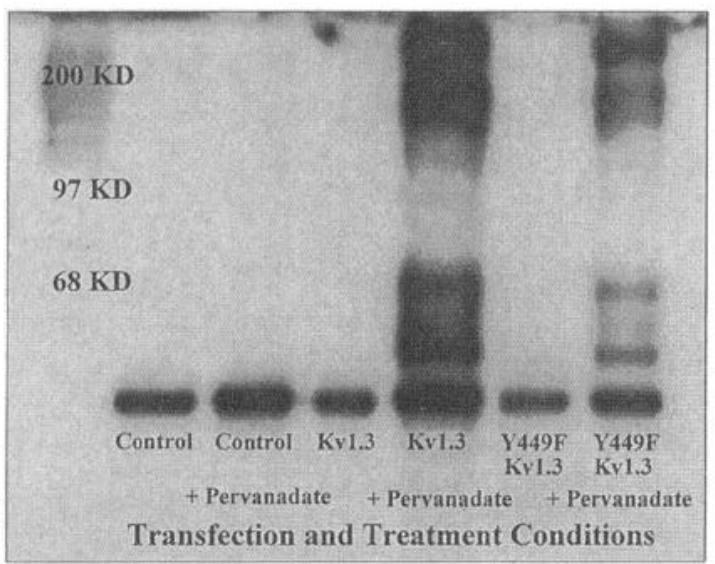

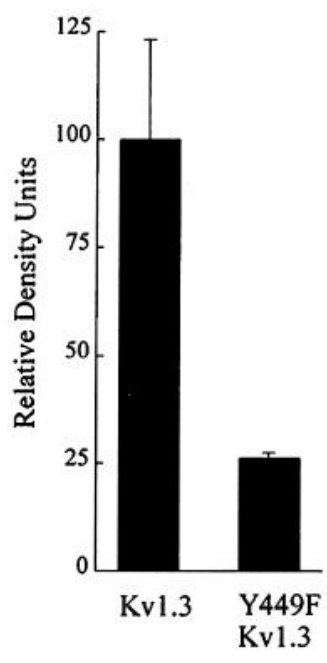

+ Pervanadate
Figure 9. Pervanadate-induced current suppression and tyrosine phosphorylation are reduced in Y449F Kv1.3 mutant channels. A, HEK 293 cells were transfected with Y449F Kv1.3, and cellattached patch recordings were made $2 \mathrm{~d}$ later. Pulse protocols and pervanadate treatment were identical to those in Figure 8. B, Pervanadate fails to suppress Y449F Kv1.3 current over time. $A$ and $B$ are representative of six individual experiments. $C$, HEK 293 cells were transfected with Control vector, $K v 1.3$, or $Y 449 F K v 1.3$. Two days after transfection, cells were treated with Pervanadate $(250 \mu \mathrm{M}, 60 \mathrm{~min})$. Triton X-100-soluble cell lysates were prepared, and tyrosine-phosphorylated proteins were immunoprecipitated with antibody PY20. The immunoprecipitated proteins were separated by SDS-PAGE, transferred to nitrocellulose, and probed with anti-Kv1.3 antiserum. $D$, Tyrosine phosphorylation of $\mathrm{Y} 449 \mathrm{~F} \mathrm{Kv} 1.3$ is lower than that of Kv1.3, as measured by quantitative immunodensitometry $(n=3)$.
The carbachol-induced suppression of Kv1.2 current is almost entirely blocked by treatment with the tyrosine kinase inhibitor genistein, and is partially reduced in a mutant channel, Y132F. Recent evidence indicates that a cellular tyrosine kinase, PYK2, is responsible for the phosphorylation and suppression of the activity of Kv1.2 (Lev et al., 1995). It will be of interest to determine whether Y428 of Kv1.2, which appears to be homologous to Y449 in Kv1.3, also plays a role in suppression of Kv1.2 current. Our results on the pervanadate-induced suppression of Kv1.3 resemble Kv1.2 suppression, in that the current amplitude decreases without apparent changes in channel kinetic properties.

It is noteworthy that tyrosine phosphorylation has multiple effects on the ligand-gated nicotinic acetylcholine receptor/channel: phosphorylation appears to regulate such diverse parameters as receptor distribution, subunit assembly, and desensitization rate (Ross et al., 1987; Hopfield et al., 1988; Qu et al., 1990; Wallace, 1995). It is possible that tyrosine phosphorylation of voltage-gated potassium channels such as Kv1.3 may also involve multiple regulatory mechanisms, but this remains to be investigated. The further determination of specific channel tyrosinephosphorylated residues, coupled with mechanistic electrophysiological and biophysical studies, is likely to yield important insights into channel function and signal transduction.

\section{REFERENCES}

Attali B, Honore E, Lesage F, Lazdunski M, Barhanin J (1992a) Regulation of a major cloned voltage-gated $\mathrm{K}$ channel from human $\mathrm{T}$ lymphocytes. FEBS Lett 303:229-232.

Attali B, Romey G, Honore E, Schmid A, Mattei MG, Lesage F, Richard P, Barhanin J, Lazdunski M (1992b) Cloning functional expression and regulation of two potassium channels in human T lymphocytes. J Biol Chem 267:8650-8657.

Bourgoin S, Grinstein S (1992) Peroxides of vanadate induce activation of phospholipase D in HL-60 cells. J Biol Chem 267:1908-1916.

Bowlby MR, Levitan IB (1995) Block of cloned voltage-gated potassium channels by the second messenger diacylglycerol independent of protein kinase C. J Neurophysiol 73:2221-2229. 
Brugge JS, Colton PC, Queral AE, Barrett JN, Nonner D, Keane RW (1985) Neurones express high levels of a structurally modified activated form of pp60 $0^{\mathrm{c}-\mathrm{src}}$. Nature 316:554-557.

Busch AE, Varnum MD, North RA, Adelman JP (1992) An amino acid mutation in a potassium channel that prevents inhibition by protein kinase C. Science 255:1705-1707.

Cadena DL, Gill GN (1992) Receptor tyrosine kinases. FASEB J 6:2332-2337.

Cahalan MD, Chandy KG, DeCoursey TE, Gupta S (1985) A voltagegated potassium channel in human $\mathrm{T}$ lymphocytes. $\mathrm{J}$ Physiol (Lond) 358:197-237.

Cai Y-C, Douglass J (1993) In vivo and in vitro phosphorylation of the T lymphocyte type $n$ (Kv1.3) potassium channel. J Biol Chem 268:23720-23727.

Covarrubias M, Wei A, Salkoff L, Vyas TB (1994) Elimination of rapid potassium channel inactivation by phosphorylation of the inactivation gate. Neuron 13:1403-1412.

Douglass J, Osborne PB, Cai YC, Wilkinson M, Christie MJ, Adelman JP (1990) Characterization and functional expression of a rat genomic DNA clone encoding a lymphocyte potassium channel. J Immunol 144:4841-4850

Drain P, Dubin AE, Aldrich RW (1994) Regulation of Shaker $\mathrm{K}^{+}$channel inactivation gating by the cAMP-dependent protein kinase. Neuron 12:1097-1109

Fantus IG, Kadota S, Deragon G, Foster B, Posner BI (1989) Pervanadate [peroxide(s) of vanadate] mimics insulin action in rat adipocytes via activation of the insulin receptor by tyrosine kinasc. Biochemistry 28:8864-8871.

Graham FL, Smiley J, Russell WC, Narin G (1977) Characteristics of a human cell line transformed by DNA from human adenovirus type 5 . J Gen Virol 36:59-74.

Grinstein S, Fuyura W, Lu DJ, Mills GB (1990) Vanadate stimulates oxygen consumption and tyrosine phosphorylation in electropermeabilized human neutrophils. J Biol Chem 265:318-327.

Grissmer S, Dethlefs B, Wasmuth JJ, Goldin AL, Gutman GA, Cahalan MD, Chandy KG (1990) Expression and chromosal localization of a lymphocyte $\mathbf{K}^{+}$channel gene. Proc Natl Acad Sci USA 87:9411-9415.

Hanley MR (1988) Proto-oncogenes in the nervous system. Neuron $1: 175-182$

Hopfield JF, Tank DW, Greengard P, Huganir RL (1988) Functional modulation of the nicotinic acctylcholine rcceptor by tyrosinc phosphorylation. Nature 336:677-680.

Huang X-Y, Morielli AD, Peralta EG (1993) Tyrosine kinase-dependent suppression of a potassium channel by the $G$ protein-coupled $\mathrm{ml}$ muscarinic acetylcholine receptor. Cell 75:1145-1156.

Hunter T (1995) Protein kinases and phosphatases: the yin and yang of protein phosphorylation and signalling. Cell 80:225-236.

Kaczmarek LK, Levitan IB (1987) Neuromodulation: the biochemical control of neuronal excitability. New York: Oxford UP.

Kues WA, Wunder F (1992) Heterogeneous expression patterns of mammalian potassium channel genes in developing and adult rat brain. Eur J Neurosci 4:1296-1308.

Kupper J, Bowlby MR, Marom S, Levitan IB (1995) Intracellular and extracellular amino acids that influence C-type inactivation and its modulation in a voltagc-depcndent potassium channel. Pflügers Arch 430:1-11.

Lev S, Moreno H, Martinez R, Canoll P, Peles E, Musacchio JM, Plowman GD, Rudy B, Schlessinger J (1995) Protein tyrosine kinase PYK2 involved in $\mathrm{Ca}^{2+}$-induced regulation of ion channel and MAP kinase functions. Nature 376:737-745.

Levitan IB (1994) Modulation of ion channels by protein phosphorylation and dephosphorylation. Annu Rev Physiol 56:193-212.

Llinas RR (1988) The intrinsic electrophysiological properties of mammalian neurons: insights into central nervous system function. Science 242:1654-1664.
Marom S, Goldstein SAN, Kupper J, Levitan IB (1993) Mechanism and modulation of inactivation of the Kv3 potassium channel. Receptors Channels 1:81-88.

Maroney AC, Qureshi SA, Foster DA, Brugge JS (1992) Cloning and characterization of a thermolabile $v$-src gene for use in reversible transformation of mammalian cells. Oncogene 7:1207-1214.

Marshall J, Molloy R, Moss GWJ, Howe JR, Hughes TE (1995) The jellyfish green fluorescent protein: a new tool for studying ion channel expression and function. Neuron 14:211-215.

Pandiella A, Magni M, Lovisolo D, Meldolesi J (1989) The effects of epidermal growth factor on membrane potential. J Biol Chem 264:12914-12921.

Pawson T (1995) Protein modules and signalling networks. Nature 373:573-580.

Payet MD, Dupuis G (1992) Dual regulation of the $\mathrm{N}$ type $\mathrm{K}^{+}$channel in Jurkat $\mathrm{T}$ lymphocytes by protein kinases $\mathrm{A}$ and $\mathrm{C}$. J Biol Chem 267:18270-18273.

Qu Z, Moritz E, Huganir RL (1990) Regulation of tyrosine phosphorylation of the nicotinic acetylcholine receptor at the rat neuromuscular junction. Neuron 2:367-378.

Ross AF, Rapuano M, Schmidt JH, Prives JM (1987) Phosphorylation and assembly of nicotinic acetylcholine receptor subunits in cultured chick muscle cells. J Biol Chem 262:14640-14647.

Sambrook J, Fritsch EF, Maniatas T (1989) Molecular cloning: a laboratory manual. Cold Spring Harbor, NY: Cold Spring Harbor Laboratory.

Shi G, Kleinklaus AK, Marrion NV, Trimmer JS (1994) Properties of $\mathrm{Kv} 2.1 \mathrm{~K}^{+}$channels expressed in transfected mammalian cells. J Biol Chem 269:23204-23211.

Songyang Z, Carraway KL, Eck MJ, Harrison SC, Feldman RA, Mohammadi M, Schlessinger J, Hubbard SR, Smith DP, Eng C, Lorenzo MJ, Ponder BAJ, Mayer BJ, Cantley LC (1995) Catalytic specificity of protein-tyrosine kinases is critical for selective signalling. Nature 373:536-539.

Strong M, Chandy KG, Gutman GA (1995) HSP70 interacts with the Kv1.3 $\mathrm{K}^{+}$channel protein during biosynthesis (Abstr). Biophys $\mathrm{J}$ 68:354A

Swanson R, Marshall J, Smith JS, Williams JB, Boyle MB, Folander K, Luneau CJ, Antanavage J, Oliva C, Buhrow SA, Bennett C, Stein RB, Kaczmarek LK (1990) Cloning and expression of cDNA and genomic clones encoding three delayed rectifier potassium channels in rat brain. Neuron 4:929-939.

Timpe LC, Fantl WJ (1994) Modulation of a voltage-activated potassium channel by peptide growth factor receptors. J Neurosci 14:195-201.

Wallace BG (1995) Regulation of the interaction of nicotinic acetylcholine receptors with the cytoskeleton by agrin-activated protcin tyrosinc kinase. J Cell Biol 128:1121-1129.

Wang JYJ (1988) Antibodies for phosphotyrosine: analytical and preparative tool for tyrosyl-phosphorylated proteins. Anal Biochem 172:1-7.

Wang YT, Salter MW (1994) Regulation of NMDA receptors by tyrosine kinases and phosphatases. Nature 369:233-235.

White MF, Kahn CR (1994) The insulin signaling system. J Biol Chem 269:1-4.

Wilson GF, Kaczmarek LK (1993) Modc-switching of a voltagc-gated cation channel is mediated by a protein kinase A-regulated tyrosine phosphatase. Nature 366:433-438.

Zor U, Ferber E, Gergely P, Szucs K, Dombradi V, Goldman R (1993) Reactive oxygen species mediate phorbol ester-regulated tyrosine phosphorylation and phospholipase $\mathrm{A}_{2}$ activation: potentiation by vanadate. Biochem J 295:879-888. 